\title{
Contact Conductance Determination using Infrared Thermography
}

\author{
by Jean-Marie BUCHLIN ${ }^{\star}$, Mathieu DELSIPÉ* ${ }^{\star}$ Philippe PLANQUART* and Michel RENARD** \\ *von Karman Institute for Fluid Dynamics, Rhode-Saint-Genèse, Belgium, buchlin@vki.ac.be \\ ** DREVER Int. SA, Angleur, Belgium, renard@drever.be
}

\begin{abstract}
An experimental investigation is carried out on a semi-industrial prototype of regenerative roll quench system. It allows the determination of the thermal contact conductance between a roll and a moving strip. The application of the quantitative infrared thermography leads to the angular evolution of the strip temperature while the mean roll temperature is obtained by using thermocouples connected to a wireless telemetry data acquisition system.

The experimental facility and the thermal model associated to the thermal conductance determination are presented. The results emphasize the effect of operating parameters such as the velocity, initial temperature and tensile strength of the strip. Modeling of the interfacial thermal conductance is finally proposed.
\end{abstract}

\section{Introduction}

The knowledge of heat conductance between two solids is often required when designing thermal systems. A typical example is the continuous annealing of moving strip based on the roll quench process where the hot strip is cooled through contact with cold rolls [1]. The overall heat transfer coefficient depends strongly on the thermal contact resistance between the strip and the rolls. Literature shows that such a parameter is function of the nature of the material, surface roughness, temperature level and contact pressure, which is function of the tensile strength [2].

An experimental investigation has been carried out at the von Karman Institute on a semi-industrial prototype of regenerative roll quench system to establish a correlation of the thermal contact conductance.

\section{Experimental facility}

A dedicated facility, called RRF (Roll Regenerative Furnace), has been constructed, a schematic of which is shown in Fig. 1.

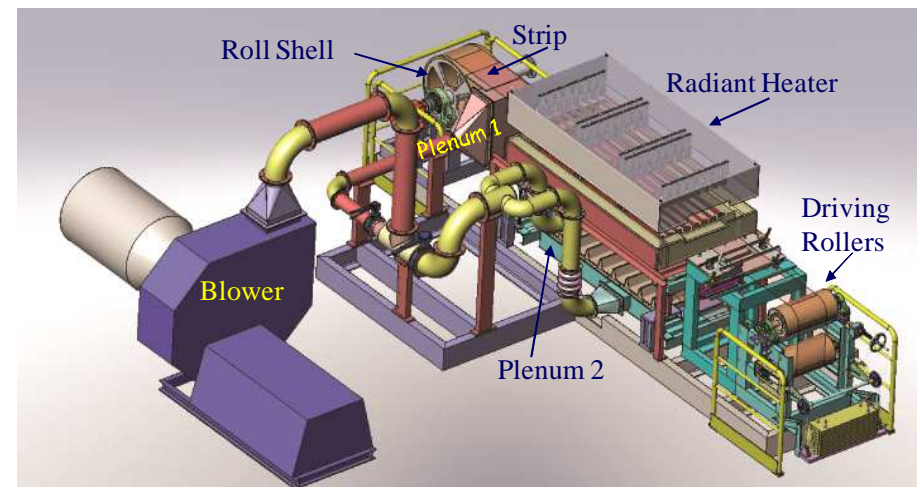

Fig. $13 D$ schematic of the RRF facility

It consists of a steel band of $0.3 \mathrm{~m}$ wide and $0.3 \mathrm{~mm}$ thick, entrained by a pair of rolls and passing through a radiant heating unit to get a maximum temperature of $650^{\circ} \mathrm{C}$. The strip is put in contact with a roll of $0.8 \mathrm{~m}$ in diameter and $0.02 \mathrm{~m}$ thick. The entraining roll is equipped with tachymeter and strain gauges, all connected to the electrical power cabinet of command, to monitor in real-time the velocity and strength of 
the strip, respectively. This latter is adjusted by varying the force of a mechanical tensor by means of metal cast weights. The line velocity,$U$, may vary from $0.25 \mathrm{~m} / \mathrm{s}$ to $0.75 \mathrm{~m} / \mathrm{s}$. An array of air jets located at plenum 1 (Figure 1) cools the roll to maintain its initial (inlet) temperature, $T_{R O}$, constant.

Figure 2 provides a schematic of the instrumentation implemented in the roll-strip test section. Two identical combs of 5 thermocouples with $0.5 \mathrm{~mm}$ in size, instrument the roll shell; one is placed on the median line of the roll and the other is off-centered close to the edge. For each comb the thermocouples are located in depth at $0.2 \mathrm{~mm}, 5 \mathrm{~mm}, 10 \mathrm{~mm}, 15 \mathrm{~mm}$ and $19.8 \mathrm{~mm}$ from the external surface of the roll, respectively. Prior to be inserted in the roll, all the thermocouples are calibrated in a thermostatic bath with a control temperature of $0.1^{\circ} \mathrm{C}$. The thermal contact inside the roll is ensured by coating the thermocouples with high thermal conductivity glue. Regular checking of calibration is performed before each test. The thermocouples are connected to a data acquisition card, part of a WIFI telemetry unit mounted on the axis of the roll. The signal received on PC is treated by dedicated software developed on Labview and Signal Express platforms.

A SC3000 IR camera scans the external black painted face of the strip at the roll location. Markers are positioned at equal interval to provide reference angular position on the thermograms, which are then processed by an in-house DIP program to obtain the thermal mapping of the strip. Two pyrometers scan also the strip; the first is positioned at the exit of the heating chamber and the second downstream the roll. They allow the continuous monitoring of the strip temperature at the inlet and outlet of the test section.

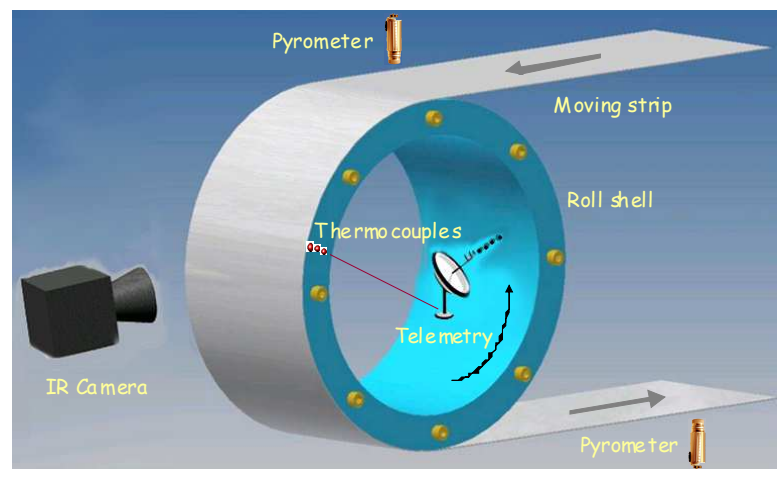

Figure 2: Measurement techniques implemented on the roll-strip test section

\section{Typical results}

The established thermal regime is characterized by a periodic behavior. Figure 3 shows a cycle of the roll temperature distribution.

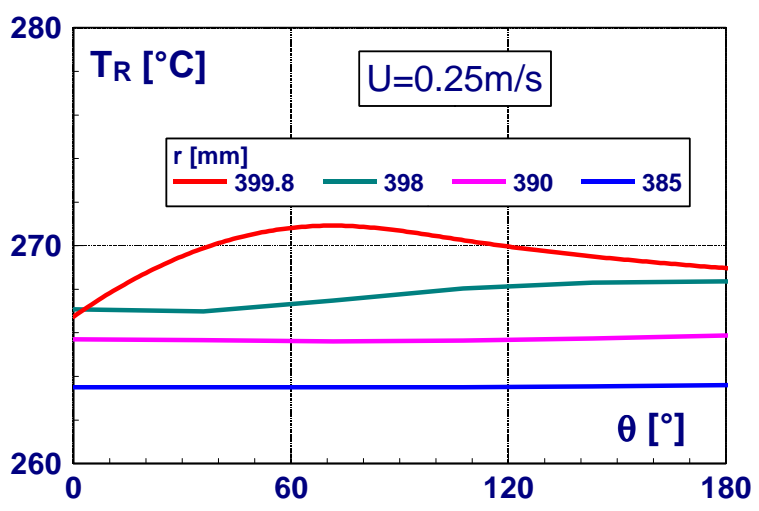

Figure 3. Angular evolution of the temperature in the roll thickness during one cycle. 
The strip temperature is inferred from false-color thermograms, a typical example of which is depicted in Figure 4a. Such thermals mappings allow the assessment of the transversal distribution of the strip temperature as shown in Figure $4 \mathrm{~b}$. The central region of the strip exhibits a fairly uniform transversal distribution. Figure 4c plots the typical angular distribution of $T_{S}$ along the central axis of the strip. The asymptotic trend noticed in Figure $4 \mathrm{c}$ indicates that the heat exchange between the roll and the strip is achieved at about $40^{\circ}$.

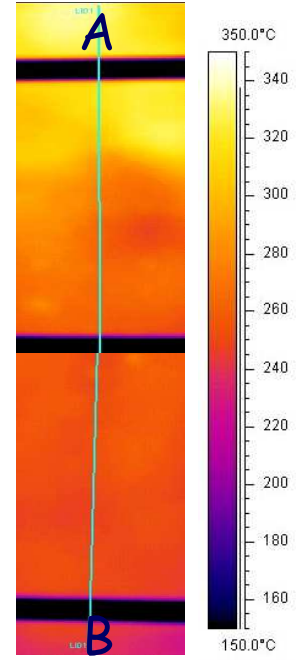

(a) IR Thermogramme

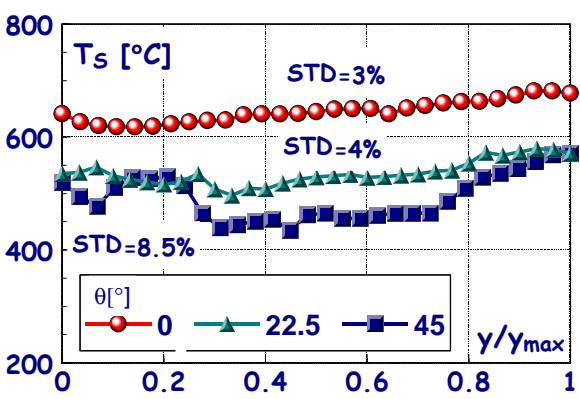

(b) Transversal distribution of $T_{S}$

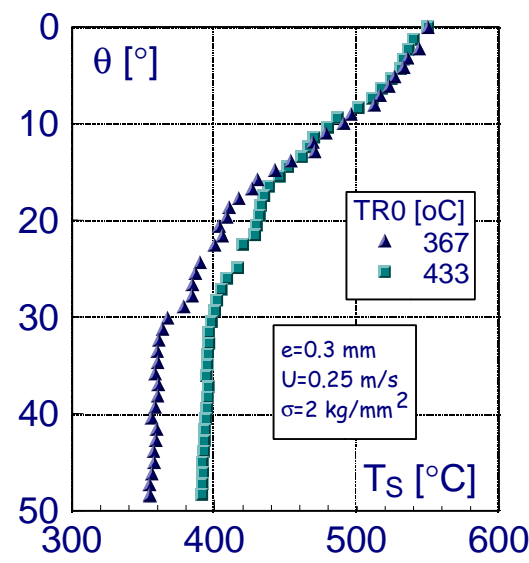

(c) Angular evolution of $T_{S}$

Figure 4: Illustrative results

The thermal contact conductance (TCC) determination is based on a cycle of the established regime. In accordance with the engineering model developed in [3] to estimate the performance of an industrial RRF system, its definition is:

$$
T C C=\frac{q_{T C C}}{\left(T_{S}-T_{R m}\right)}
$$

Due to the small strip thickness, the fin theory is applied to determine the heat flux $q_{T C C}$ as follows:

$$
q_{T C C}=-\rho_{s} C_{s} e_{s} \cdot \frac{U}{R_{R}} \cdot \frac{d T_{s}}{d \theta}-q_{e n v}
$$

Figure 5 illustrates the procedure to determine $q_{T C C}$. A dedicated smooth curve fitting allows accurate computation of the derivative of the angular evolution of the strip temperature, $T_{S}$, as illustrated in Figure $5 a$. The heat losses, $q_{\text {erv }}$, are evaluated from convection and radiation models detailed in [3]. Figure $5 b$ plots the angular variation of $q_{T C C}$ : the heat exchange between the strip and the roll starts with maximum plateau up to approximately $\theta=10^{\circ}$ and decreases gradually to 0 when $\theta$ approaches $40^{\circ}$.

The mean temperature, $T_{R M}$, through the roll thickness is computed following an enthalpy approach:

$$
T_{R m}=\int_{R_{R}-e_{R}}^{R_{R}} \rho_{R} C_{R} \cdot u \cdot T_{R} \cdot d r / \int_{R_{R}-e_{R}}^{R_{R}} \rho_{R} C_{R} \cdot u \cdot d r
$$

Where $R_{R}$ and $e_{R}$ are the external radius and the thickness of the roll, respectively. 
Figure 6 shows that once the cyclic regime is developed, $T_{R M}$ keeps a constant value, which is very close to $T_{\text {RO. }}$

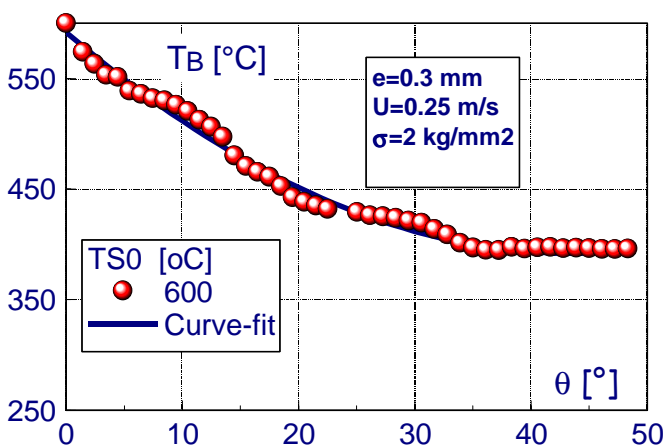

(a) Curve-fitting of $T_{S}$

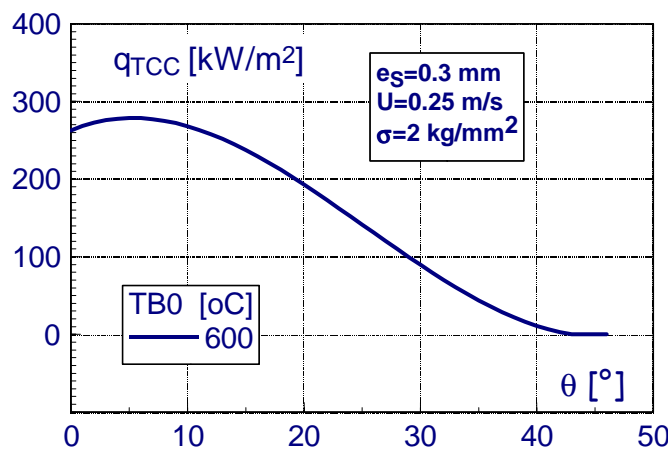

(b) Angular evolution of $\mathrm{q}_{\mathrm{TCC}}$

Figure 5: Calculation of $q_{T C C}$.

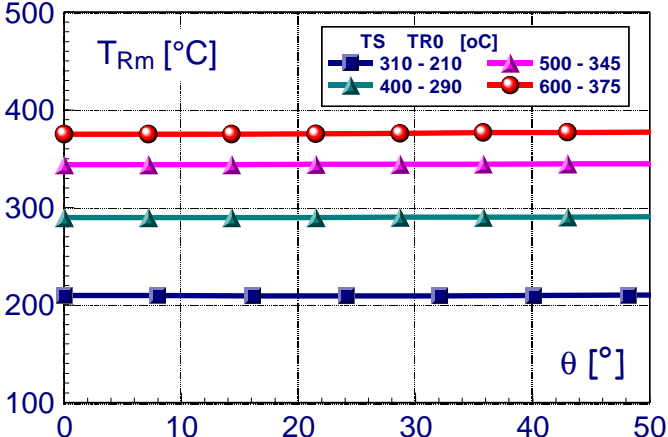

Figure 6: Angular evolution of $\mathrm{T}_{\mathrm{RM}}$.

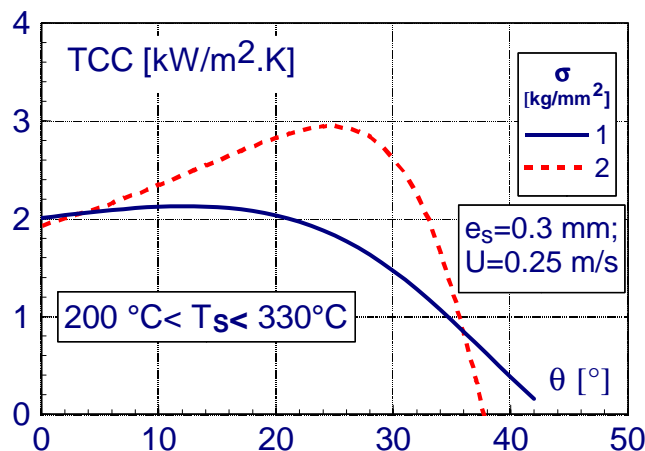

Figure 7: Angular evolution of TCC.

As an example, Figure 7 plots the angular evolution of TCC for two values of the tensile force, $\sigma$, applied to the strip. TCC improves clearly when $\sigma$ increases.

In the foreseen design of the industrial RRF, the total angular coverage, $\theta_{c}$, of the strip on the roll is ranging from $25^{\circ}$ to $45^{\circ}$. Therefore a mean thermal contact conductance, $T C C_{m}$, is defined in line with that used in the engineering model [3]. The adopted definition anticipates an effect of the temperature on the value of the strip heat capacity:

$$
T C C_{m}\left(\theta_{c}\right)=\frac{\rho_{S} e_{S} U}{R_{R} \cdot \theta_{C}} \int_{T_{S o}}^{T_{S}\left(\theta_{c}\right)} C_{S}(T) \frac{d T}{\left(T_{R M}-T\right)}
$$

The effect of the different operating parameters on the strip-roll heat exchange is now analysed through $T C C_{m}$. The first parameter to be considered is the line speed, $U$. Figure 8 displays the findings for two types of strip material. The results exhibit some scattering due to the variation of other operating conditions such as the initial strip temperature, $T_{\text {So, }}$ and roll-strip temperature difference, $\Delta T_{S R o}$. However, the data fall in the range of $2 \mathrm{~kW} / \mathrm{m} 2 . \mathrm{K}$ to $4.5 \mathrm{~kW} / \mathrm{m} 2 . \mathrm{K}$ in agreement with the sparse literature existing on this topic $[4,5]$. Keeping in mind that heat transfer coefficient such as TCC are generally determined with a confidence not better than $\pm 15 \%$, one can conclude from Figure 8 that rising the line velocity produces moderate increase of the thermal conductance. 
Figure 9a shows that the heat exchange improves to some extent as the initial strip temperature, $T_{\text {so, }}$, increases. However the trend becomes negligible above $400^{\circ} \mathrm{C}$. Since in the industrial application foreseen the strip temperature can be of the order of $800^{\circ} \mathrm{C}$, the $T C C$-values displayed in Figure 9a can be considered as the maximum ones. Similarly, enhancement of $T C C_{m}$ of about $20 \%$ can be noticed in Figure $9 \mathrm{~b}$ when the initial temperature difference, $\Delta T_{S R O}$, between the strip and the roll exceeds $150^{\circ} \mathrm{C}$.
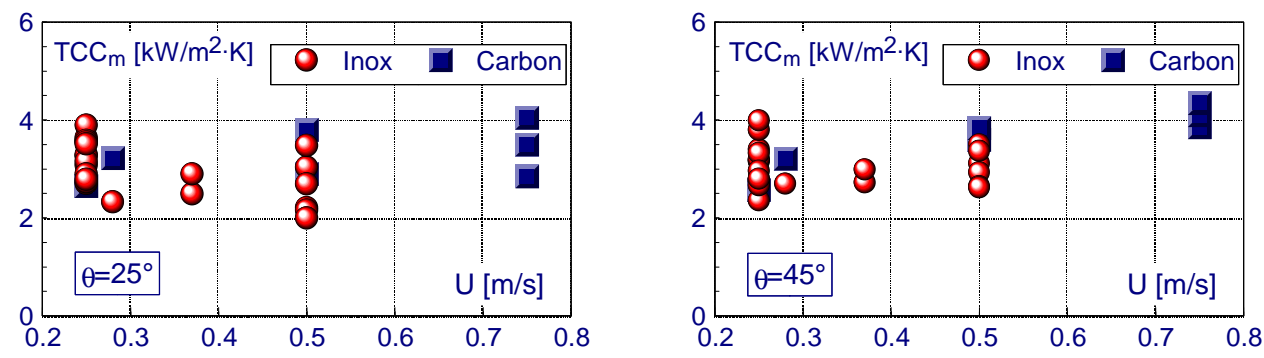

Figure 8: Effect of line speed on the heat exchange.
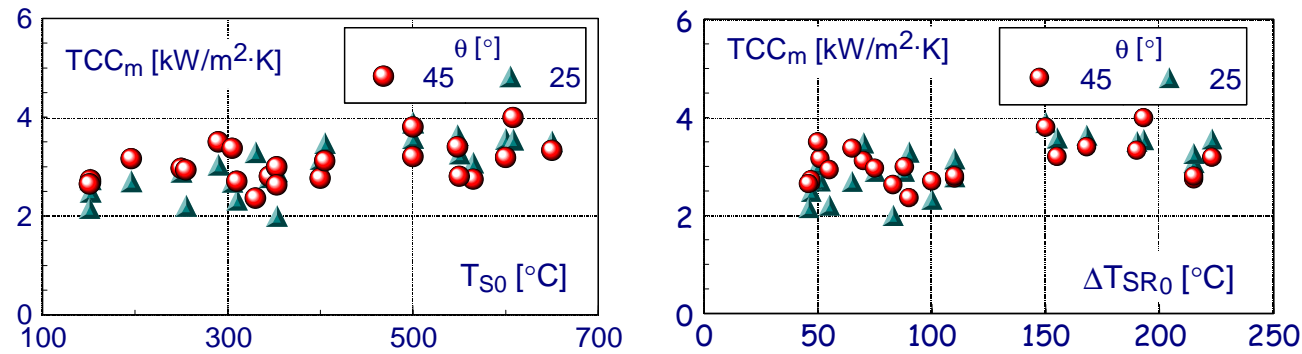

Figure 9: Effect of the initial thermal conditions on the heat exchange.

On the basis of the present data an attempt is undertaken to evaluate the interfacial thermal contact conductance $T C C_{i}$, quantity which is very difficult even impossible to measure experimentally. Assuming thermal resistances in series from the temperature of the strip surface measured by the infrared camera to the mean temperature of the roll representative of an effective thickness $e_{e f}$, the final expression of $T C C_{i}$ is:

$$
T C C_{i}=\left[\frac{1}{T C C_{m}}-\frac{e_{S}}{k_{S}}-\frac{e_{e f, R}}{k_{R}}\right]^{-1}
$$

The effective roll thickness can be estimated from the thermal penetration theory, $e_{e f, R}=\sqrt{\frac{\theta_{c} \cdot \alpha_{R} \cdot U}{R_{R}}}$ where $\alpha_{R}$ is the thermal diffusivity of the roll material.

Figure 10 shows the estimated $T C C i$-values versus the $T C C_{m}$-values obtained experimentally. The $T C C_{i}$ values vary from $3 \mathrm{~kW} / \mathrm{m} 2 . \mathrm{K}$ to $10 \mathrm{~kW} / \mathrm{m} 2 . \mathrm{K}$. Such results agree fairly well with classical data published in literature for metallic contacts [6] 


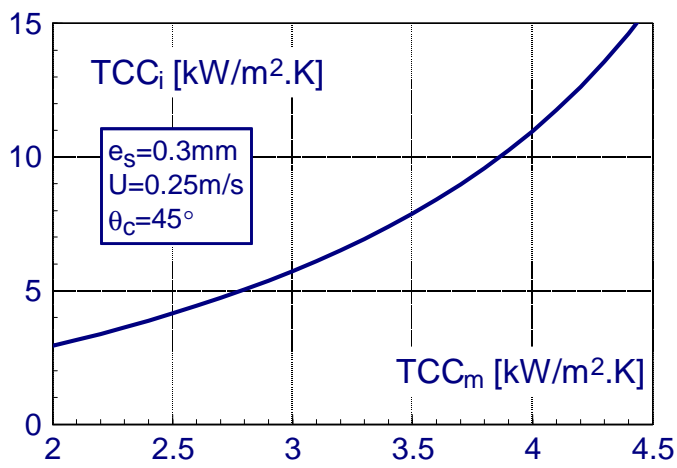

Figure 10 : Interfacia0l conductance at strip-roll contact

\section{Conclusions}

An experimental study of the thermal contact conductance between a moving strip and a roll is presented. A dedicated semi-industrial facility allowing strip temperature up to $650^{\circ} \mathrm{C}$ is used. Its main instrumentation involves quantitative infrared thermography and telemetric thermometry.

Simple analytical model supports data processing and physical interpretation. It allows the determination of the angular evolution of the thermal contact conductance based on the mean temperature of the roll. The strip-to-roll heat exchange is achieved over an angular coverage not exceeding $45^{\circ}$. The results shows that the strip tensile strength is an important controlling parameter of the thermal performance.

The value of the thermal contact conductance averaged over the angular coverage, $T C C_{\mathrm{m}}$, is ranging between $2 \mathrm{~kW} / \mathrm{m}_{2} \mathrm{~K}$ et $4.5 \mathrm{~kW} / \mathrm{m} 2 \mathrm{~K}$. The increase of the line velocity leads to a slight improvement of $T C C_{m}$. Moreover, higher is the initial strip temperature and roll-strip temperature difference better is $T C C_{m}$.

Modelling of thermal resistances in series using the experimental $T C C_{m}$-values provides an estimation of the interfacial contact conductance. Findings are in good agreement with published data.

\section{ACKNOWLEDGMENT}

The authors are indebted to the Walloon region for its continuous support along this research programme.

\section{NOMENCLATURE}

$\begin{array}{ll}C & \text { specific heat } \\ e & \text { thickness } \\ T C C & \text { conductance } \\ q & \text { heat flux } \\ R & \text { radius } \\ T & \text { temperature } \\ U, u & \text { velocity } \\ \text { subscript } \\ \text { c } & \\ \text { env } & \text { coverage } \\ \text { i } & \text { environment } \\ \text { m } & \text { interfacial } \\ & \text { mean }\end{array}$

$(\mathrm{J} / \mathrm{kg} \cdot \mathrm{K})$
$(\mathrm{m})$
$\left(\mathrm{W} / \mathrm{m}^{2} \cdot \mathrm{K}\right)$
$\left(\mathrm{W} / \mathrm{m}^{2}\right)$
$(\mathrm{m})$
$\left({ }^{\circ} \mathrm{C}\right)$
$(\mathrm{m} / \mathrm{s})$




\section{REFERENCES}

[1] HAMEL, G. \& MOLIXE, F., "Le recuit continu des tôles minces à Sollac Montataire, " La Revue de Métallurgie-CIT, pp 968-978, ( 1988).

[2] OKURA Mineki, MAKINO Hidetaka, TANAKA Yoshiki, IWAYA Jiro and MAEDA Hiroyuki : Improvement in First Cooling Technique (Roll Quench and Water Quench) and the Properties of Products. Developments in the Annealing of Sheets Steels. Eds. R Pradhan and I. Gupta - the Mineral, Metal and Material Society, 1992.

[3] BUCHLIN Jean-Marie, LABOUREUR Delphine, PLANQUART Philippe, \& RENARD Michel : Modélisation d'un régénérateur à rouleaux. Congrès Français de Thermique, Thermique et Contexte Incertain , Gérardmer, mai 2013.

[4] OKURA, M., MAKINO, H., TANAKA, Y., IWAYA, J., MAEDA, H., "Improvement in First Cooling Technique (Roll Quench and Water Quench) and the Properties of Products". In R Pradhan and I. Gupta Eds. Developments in the Annealing of Sheets Steels.- The Mineral, Metal and Material Society (1992).

[5] FUKUDA, S. and OHKUBO, Y., "Heat Transfer characteristics of roller quench system in continuous annealing line,", In I. Tanasawa and N. Lior Eds. Heat and mass transferring materials processing: Hemisphere publishing corporation, pp 501-513, (1992).

[6] HOLMAN Jack Phillip, "Heat Transfer”, McGraw Hill Book, Fourth Edition, 1976. 